\title{
Effect of Adding Different Amounts of Graphite Nanoplatelets on Structural, Thermal, Mechanical and Viscoelastic Properties of Vinylester Based Composites Cured at $25^{\circ} \mathrm{C}$
}

\author{
José A. Jofre-Reche, ${ }^{1}$ Cristina Alia-García, ${ }^{2}$ Juan C. Suárez-Bermejo, ${ }^{2}$ \\ José M. Arenas-Reina, ${ }^{2}$ José Miguel Martín-Martínez ${ }^{1}$ \\ ${ }^{1}$ Adhesion and Adhesives Laboratory, University of Alicante, 03080 Alicante, Spain \\ ${ }^{2}$ Department of Materials Science, Structural Materials Research Centre (CIME), \\ Technical University of Madrid, Madrid 28040, Spain
}

\begin{abstract}
Different amounts $(0.1-5 w t \%)$ of graphite nanoplatelets (GNs) were added to vinylester (VE) for improving the properties of the composites cured at $25^{\circ} \mathrm{C}$. The addition of $0.1 w t \%$ GN only increased the $T_{\mathrm{g}}$ and the thermal stability of the composite cured at $25^{\circ} \mathrm{C}$. Furthermore, the addition of GN increased both the tensile strength and elongation-at-break of the composites cured at $25^{\circ} \mathrm{C}$, but the effect of adding GN was less important when cured at $100^{\circ} \mathrm{C}$. The improved properties of the composites were ascribed to the interactions between the oxygen species on the $\mathrm{GN}$ edges and the $\mathrm{C}=0$ and $\mathrm{OH}$ groups in the VE monomer, and to the higher fraction of the partially crosslinked polymer within the matrix. POLYM. COMPOS., 00:000-000, 2017. (C) 2017 Society of Plastics Engineers
\end{abstract}

\section{INTRODUCTION}

Vinylesters (VEs) are among the most important classes of thermosets that combine the chemical, mechanical and thermal properties of epoxies with the rapid cure of the unsaturated polyesters [1]. VE resins show high chemical and hydrolytic resistance, relatively good toughness, high modulus and good thermal and electrical insulation property $[2,3]$. Because of these properties, VE is widely used in structural adhesive joints and composites for different industrial applications and vehicle construction (e.g., automotive, aeronautical, naval) [4]. Furthermore, VE shows faster cure rate than the unsaturated polyesters, both having relatively similar chemical structure [5]. However, even for extended periods of time or outdoor exposure, the complete

Correspondence to: J.M. Martín-Martínez; e-mail: jm.martin@ua.es DOI 10.1002/pc.24283

Published online in Wiley Online Library (wileyonlinelibrary.com).

(C) 2017 Society of Plastics Engineers cure of the VE cannot be achieved, thereby reducing their level of performance [6-9].

The superior performance of the polymer/graphene nanocomposites in noticeable improvement of the mechanical, thermal, gas barrier, electrical and flame retardant properties, as compared with the neat polymer, have been demonstrated [10-13]. The improvement of the properties of those nanocomposites depends on the distribution of the graphene or graphite layers in the polymer matrix, as well as on the interfacial interactions.

Several studies on expanded and exfoliated graphite/ polymer composites have been published, including epoxy [14], polymethylmethacrylate [15], polypropylene [16], polyethylene [17], polystyrene [18], poly( $p$-phenylene sulphide) [19], polyamide [20] and polyaniline [21], among others. However, the addition of graphene or graphite layers to the VE resin has not yet been studied sufficiently [22-24]. Chaturvedi et al. [22] added $0.2 \mathrm{wt} \%$ modified graphene into VE resin in different solvents using ultrasonication and concluded that the solvent played a key role in imparting toughness to the resulting composite. Swain [23] studied the mechanical, thermal and electrical properties of unsaturated polyester resin (UPR) containing graphene nanosheets and a homogeneous dispersion of the sheets in the polymer matrix, a strong interfacial adhesion and enhanced mechanical properties were achieved. Almajid et al. [25] prepared VE nanocomposites with graphene and carbon nanotubes and studied their thermal and viscoelastic behaviour, flexural properties, hardness, scratch resistance and electrical conductivity. They concluded that the electrical conductivity showed a percolation threshold in the composites containing $2 \mathrm{wt} \%$ graphene, and a high degree of dispersion was obtained. As a consequence, the corrosion resistance of the resulting composite coatings on metal exhibited better performance than the neat 


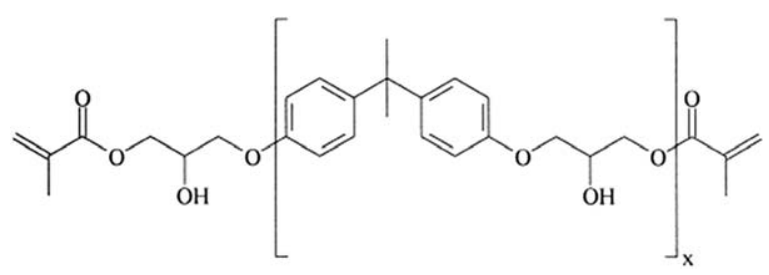

FIG. 1. Structure of the vinyl ester monomer.

VE. However, none of these studies considered the influence of the curing temperature of the VE-GN composites.

Alia et al. [26] have subjected VE resin to various postcuring temperatures $\left(50-140^{\circ} \mathrm{C}\right)$ for $1 \mathrm{~h}$, and the changes in the structure and in several properties of the composites were assessed. They have shown that the degree of crosslinking of the VE polymer depended on the post-cure temperature, and the cure began to be completed above $100^{\circ} \mathrm{C}$; furthermore, the gel formation in the VE was observed for post-cure temperatures below $100^{\circ} \mathrm{C}$. In this study, the existence of interactions between the surface groups on graphite nanoplatelets (GNs) and the $\mathrm{C}=\mathrm{O}$ and $\mathrm{OH}$ moieties of the VE monomer are proposed, and their influence on the extent of crosslinking of the VE resin cured at $25^{\circ} \mathrm{C}$ and on the thermal, viscoelastic and mechanical properties of the VE-GN composites are analyzed. On the other hand, because of an almost complete cure of VE resin is produced around $100^{\circ} \mathrm{C}$ [26], the VE-GN mixtures were cured at $25^{\circ} \mathrm{C}$ (temperature at which the cure of the VE is not completed) and their properties were compared with the ones of the VE-GN composites cured at $100^{\circ} \mathrm{C}$.

\section{EXPERIMENTAL}

\section{Materials}

Graphite nanoplatelets Avangrp@ (AVANZARE Innovación Tecnológica SL, La Rioja, Spain) with a lamellar structure were used. The graphite nanoplatelets (GNs) have dimensions of $2 \times 5$ microns and are less than $10 \mathrm{~nm}$ thick. The density of the nanoplatelets is lower than $0.2 \mathrm{~g} / \mathrm{cm}^{3}$, and they have high thermal conductivity (about 3,000 W/mK), high Young's modulus (about 1,000 GPa) and high specific surface area $\left(200 \mathrm{~m}^{2} / \mathrm{g}\right)$ [27].

Two-component bisphenol-epoxy vinylester resin DION $^{\circledR}$ 9100 (Reichhold, Durham, NC) was used. The structure of the

previous study [26]. $200 \mathrm{~g}$ VE monomer and the corresponding amount of GN were placed in a glass beaker, and the mixture was stirred in Dispermix DL-B stirrer (Oliver-Batlle, Badalona, Spain) at 2,000 rpm for $90 \mathrm{~min}$. Afterwards, the mixture was stored at room temperature, and $2.5 \mathrm{wt} \%$ methyl ethyl ketone peroxide (MEKP) was added and mixed manually for $1 \mathrm{~min}$.

\section{Experimental Techniques}

Infrared Spectroscopy (ATR-IR Spectroscopy). The chemical structure of the VE-GN composites cured at 25 and $100^{\circ} \mathrm{C}$ were studied by IR spectroscopy and the multiple attenuated total reflectance mode (ATR-IR spectroscopy) was used; a diamond prism was used. The incidence angle of the IR beam was $45^{\circ}$, and 60 scans were recorded and averaged with a resolution of $4 \mathrm{~cm}^{-1}$.

Raman Spectroscopy. Raman spectra of the GN and the VE-GN composites were obtained in LabRam spectrometer (Jobin-Ivon Horiba, Kyoto, Japan) provided with a confocal microscope and three lines of laser excitation (wavelengths of 514, 632 and $785 \mathrm{~nm}$ ); the laser wavenumber used was $514 \mathrm{~nm}$ and the CCD detector was cooled by Peltier device. A resolution of $3 \mathrm{~cm}^{-1}$ was obtained in the Raman spectra.

X-Ray Photoelectron Spectroscopy (XPS). The surface chemistry of the GN was analyzed in K-Alpha Thermoscientific instrument (Thermo Fischer Scientific, Waltham, MA), using an $\mathrm{Mg} \mathrm{K}_{\alpha} \mathrm{X}$-ray source $(1,253.6 \mathrm{eV})$ with an incidence angle of $45^{\circ}$ and operating at $15 \mathrm{keV}$ and $300 \mathrm{~W}$. Prior to analysis, the GNs were outgassed in a vacuum chamber at a pressure lower than $5 \times 10^{-8}$ torr. A survey scan encompassing the region $0-1,200 \mathrm{eV}$ was first obtained with a resolution of $4 \mathrm{eV}$. In a narrower energy interval $(20 \mathrm{eV})$, high resolution XPS spectra were obtained.

Scanning Electron Microscopy (SEM). The surface morphology of the VE-GN composites was analyzed by scanning electron microscopy in JEOL JSM 5600 (Tokyo, Japan). The specimens were obtained by cooling down in liquid nitrogen for $10 \mathrm{~s}$ followed by fragmentation with a hammer. The specimens were gold coated before analysis by sputtering in argon atmosphere to improve contrast, and an electron acceleration voltage of $20 \mathrm{kV}$ was used. vinylester resin is $43-47 \mathrm{wt} \%$, and the initiators are methyl ethyl ketone peroxide (MEKP), 6wt\% cobalt naphthenate and dimethyl aniline. $2.5 \mathrm{wt} \%$ methyl ethyl ketone peroxide (MEKP) initiator was added to the VE resin in a glass container and the mixture was stirred manually at room temperature for $5 \mathrm{~min}$. Then, the mixture was allowed to cure at $25^{\circ} \mathrm{C}$ for $24 \mathrm{~h}$. In some cases, a post-cure was carried out by placing the VE cured at $25^{\circ} \mathrm{C}$ in an oven (Selecta 2000208, Barcelona, Spain) at $100^{\circ} \mathrm{C}$ for $1 \mathrm{~h}$.

Three percentages $(0.1,1$ and $5 \mathrm{wt} \%)$ of GNs were added to the VE monomer, and they were selected according to a

Confocal Laser Microscopy. The nanoplatelets distribution in the VE-GN composites was analyzed by confocal laser scanning microscopy (CLSM) in Leica TCS SPE confocal microscope (Leica Microsystems, Wetzlar, Germany).

Differential Scanning Calorimetry (DSC). The thermal properties and the glass transition temperature $\left(T_{\mathrm{g}}\right)$ of the VE-GN composites cured at 25 and $100^{\circ} \mathrm{C}$ were determined in TA Q100 DSC equipment (TA Instruments, New Castle, DE). The temperature was varied between -50 and $200^{\circ} \mathrm{C}$ 
under nitrogen atmosphere (flow rate: $50 \mathrm{ml} / \mathrm{min}$ ), and two consecutive heating runs were carried out. A heating rate of $10^{\circ} \mathrm{C} / \mathrm{min}$ was used. Whereas the existence of residual cure in the composites was obtained from the first DSC heating run, their $T_{\mathrm{g}}$ values were determined at the midpoint in the inflexion of the second DSC heating run.

Thermogravimetric Analysis (TGA). The thermal stability of the VE-GN composites cured at 25 and $100^{\circ} \mathrm{C}$ were evaluated in TA Q500 TGA equipment (TA Instruments, New Castle, DE). 10-15 mg composite was placed in a platinum crucible under nitrogen atmosphere (flow rate: $100 \mathrm{ml} / \mathrm{min}$ ), and the temperature was raised to $800^{\circ} \mathrm{C}$ by using a heating rate of $10^{\circ} \mathrm{C} / \mathrm{min}$. At the end of the experiments, the nitrogen atmosphere was replaced by oxygen (flow rate: $60 \mathrm{ml} / \mathrm{min}$ ) at $800^{\circ} \mathrm{C}$ for $15 \mathrm{~min}$ to remove the carbonized residue.

Dynamic Mechanical Thermal Analysis (DMTA). The viscoelastic properties of the VE-GN composites cured at 25 and $100^{\circ} \mathrm{C}$ were studied in TA Q800 DMA equipment (TA Instruments, New Castle, DE), and 3-point bending geometry was used. Experiments were carried out at $1 \mathrm{~Hz}$ frequency and $20 \mathrm{~mm}$ amplitude. The temperature was varied between -25 and $200^{\circ} \mathrm{C}$ by using a heating rate of $5^{\circ} \mathrm{C} / \mathrm{min}$.

Stress-Strain Tests. The tensile strength and the elongation-at-break of dog bone test specimens made with VE-GN composites cured at 25 and $100^{\circ} \mathrm{C}$ were measured according to ISO R527-1-966 standard in IBTH3630 universal testing machine (IberTest, Madrid, Spain). The pulling rate was $2 \mathrm{~mm} / \mathrm{min}$. Five replicates for each composite were measured and averaged.

\section{RESULTS AND DISCUSSION}

\section{Characterization of the GNS}

Figure 2 shows the Raman spectrum of the GNs in which the bands at 1,323 (D-mode), 2,661 (2D-mode) and $2,967 \mathrm{~cm}^{-1}$ (D $+\mathrm{G}$-mode) can be distinguished [28]. In the Raman spectrum of the GNs, the G-mode of the graphene does not appear indicating a disordered structure. Furthermore, because of the D-mode in the Raman spectrum is caused by disordered structure of the graphene, and considering the wide 2D band and the much higher intensity of the $\mathrm{D}$ band with respect to that of the $2 \mathrm{D}$ band in the Raman spectrum of the GNs of Fig. 2, the GNs are constituted by multi-layered graphene. On the other hand, the band at $1,098 \mathrm{~cm}^{-1}$ in Fig. 2 is not common in graphene nor in graphite flakes and can be ascribed to the presence of $\mathrm{O}-\mathrm{C}-\mathrm{O}$ species in the GNs.

The chemical compositions of the GNs surface were assessed by XPS, and their surface are composed of 90.1 at\% C and 9.9at\% O. Because of the relatively low amount of oxygen, most of the functional groups should

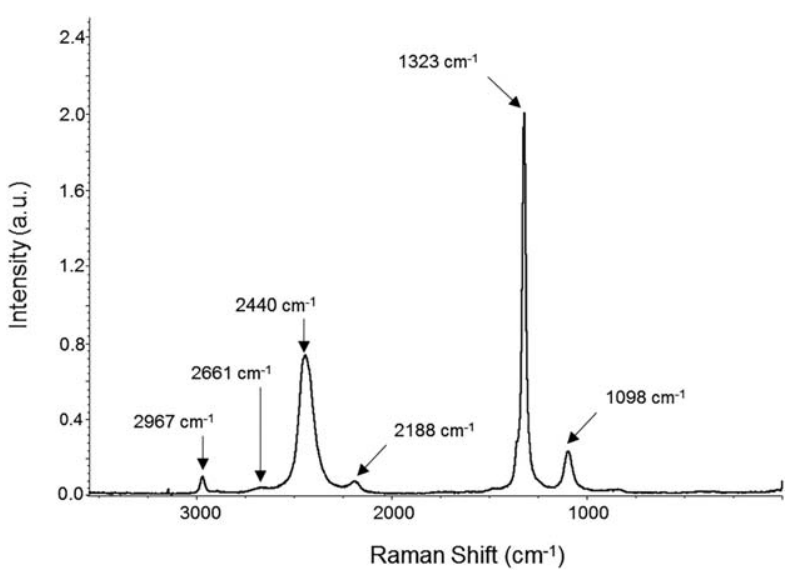

FIG. 2. Raman spectrum of the graphite nanoplatelets.

be on the edges of the nanoplatelets. The nature of the oxygen groups on the GNs edges was assessed by curve fitting of the $\mathrm{C} 1 \mathrm{~s}$ and $\mathrm{O} 1 \mathrm{~s}$ photopeaks. According to Fig. 3a, a single $\mathrm{C}-\mathrm{C}$ bond in the graphite structure at a binding energy of $284.6 \mathrm{eV}$ accounts for $66.1 \mathrm{at} \%$ and $\mathrm{C}-\mathrm{C} \mathrm{\textrm {sp } ^ { 3 }}$ species at binding energy of $285.2 \mathrm{eV}$ accounts for $19.5 \mathrm{at} \%$ on the GNs edges [29, 30]. Furthermore, the other species found on the GNs edges correspond to $\mathrm{C}-\mathrm{O}, \mathrm{C}=\mathrm{O}$ and $\mathrm{O}-\mathrm{C}=\mathrm{O}$ groups at binding energies of $286.2 \mathrm{eV}, 287.1 \mathrm{eV}$ and $289.1 \mathrm{eV}$, respectively. The $\mathrm{C}-\mathrm{O}$ species on the GNs edges account for $6.7 \mathrm{at} \%$, and they correspond to carbon atoms bonded to hydroxyl group $(\mathrm{C}-\mathrm{OH})$ and/or $\mathrm{C}-\mathrm{O}-\mathrm{C}$ epoxide group, and $4.3 \mathrm{at} \%$ of $\mathrm{C}=\mathrm{O}$ groups and $3.4 \mathrm{at} \%$ of $\mathrm{O}-\mathrm{C}=\mathrm{O}$ groups are also present on the GN edges. The existence of oxygen species on the edges of the GNs was confirmed by curve fitting of the O1s photopeak. According to Fig. 3b, 4.6at\% of O-H (binding energy: $527.7 \mathrm{eV}$ ), 56.2at\% of $\mathrm{C}=\mathrm{O}$ (binding energy: $529.9 \mathrm{eV}$ ) and 39.2at\% of $\mathrm{C}-\mathrm{O}$ (binding energy: $531.3 \mathrm{eV}$ ) species are present on the edges of the GNs.

\section{Structural Characterization of the VE-GN Composites}

Figure 4 shows the ATR-IR spectra of the VE polymer cured at 25 and $100^{\circ} \mathrm{C}$ for $1 \mathrm{~h}$. Because of the network formation in the VE polymer is a free radical copolymerization between the methacrylate moieties of the VE monomer and the styrene, the amount of $\mathrm{OH}$ groups in the $\mathrm{VE}$ polymer cured at 25 and $100^{\circ} \mathrm{C}$ should be the same. Therefore, the ATR-IR spectra of Fig. 4 were normalized to the $\mathrm{OH}$ stretching band at $3,336 \mathrm{~cm}^{-1}$. The ATR-IR spectrum of the VE polymer cured at $25^{\circ} \mathrm{C}$ shows the absorption bands corresponding to $\mathrm{OH}$ stretching at $3,336 \mathrm{~cm}^{-1}, \mathrm{C}=\mathrm{C}$ stretching at $1,635 \mathrm{~cm}^{-1}, \mathrm{C}=\mathrm{C}$ bending at 828 and $943 \mathrm{~cm}^{-1}$ (vinyl group), aromatic ring stretching and bending at 1,581 and $700 \mathrm{~cm}^{-1}$ respectively, $\mathrm{C}=\mathrm{O}$ stretching at $1,712 \mathrm{~cm}^{-1}$, and $\mathrm{C}-\mathrm{O}-\mathrm{C}$ and $\mathrm{C}-\mathrm{CO}-\mathrm{O}$ stretching at 1,233, 1,160 and $1,038 \mathrm{~cm}^{-1}$. The increase of the cure temperature to $100^{\circ} \mathrm{C}$ 


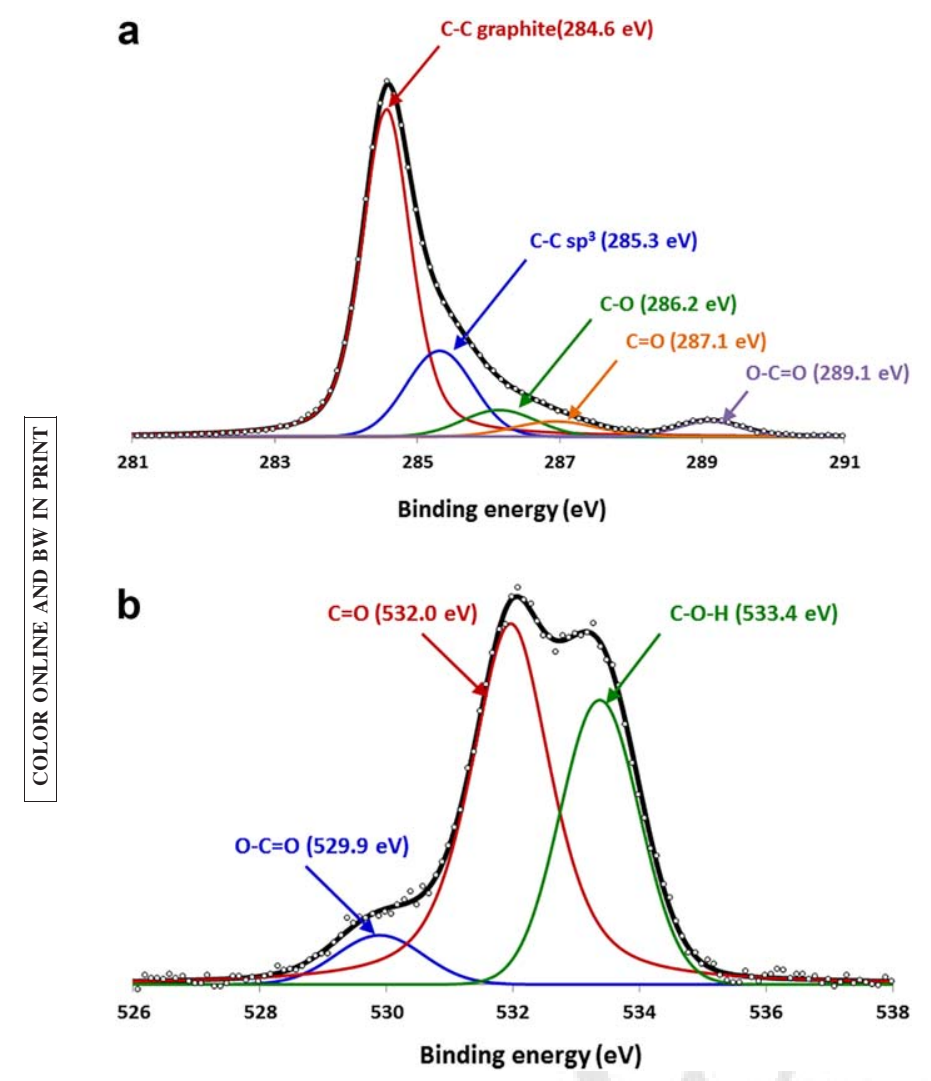

FIG. 3. (a) Curve fitting of the C1s core level of the GNs. XPS experiment. (b) Curve fitting of the O1s core level of the GNs. XPS experiment. [Color figure can be viewed at wileyonlinelibrary.com]

changes the intensity of the most bands of the VE polymer mainly the ones at $2,966 \mathrm{~cm}^{-1}(\mathrm{C}-\mathrm{H}$ stretching), 1,712, 1,233 and $1,160 \mathrm{~cm}^{-1}(\mathrm{C}=\mathrm{O}, \mathrm{C}-\mathrm{O}-\mathrm{C}$ and $\mathrm{C}-\mathrm{CO}-\mathrm{O}$ stretching) and $700 \mathrm{~cm}^{-1}$ (aromatic bending). The augmentation of the cure temperature increases the length of the VE polymer chain and the number of $\mathrm{C}=\mathrm{O}$ and $\mathrm{C}-\mathrm{O}-\mathrm{C}$ groups, i.e. higher degree of polymerization is produced in the $\mathrm{VE}$ polymer cured at $100^{\circ} \mathrm{C}$.

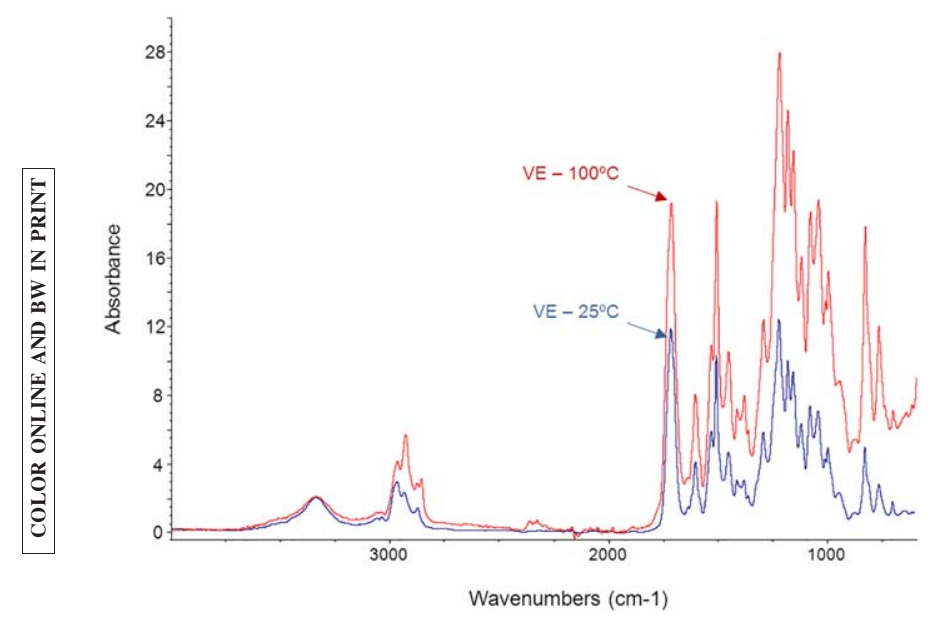

FIG. 4. ATR-IR spectra of the VE polymer cured at 25 and $100^{\circ} \mathrm{C}$. [Color figure can be viewed at wileyonlinelibrary.com]
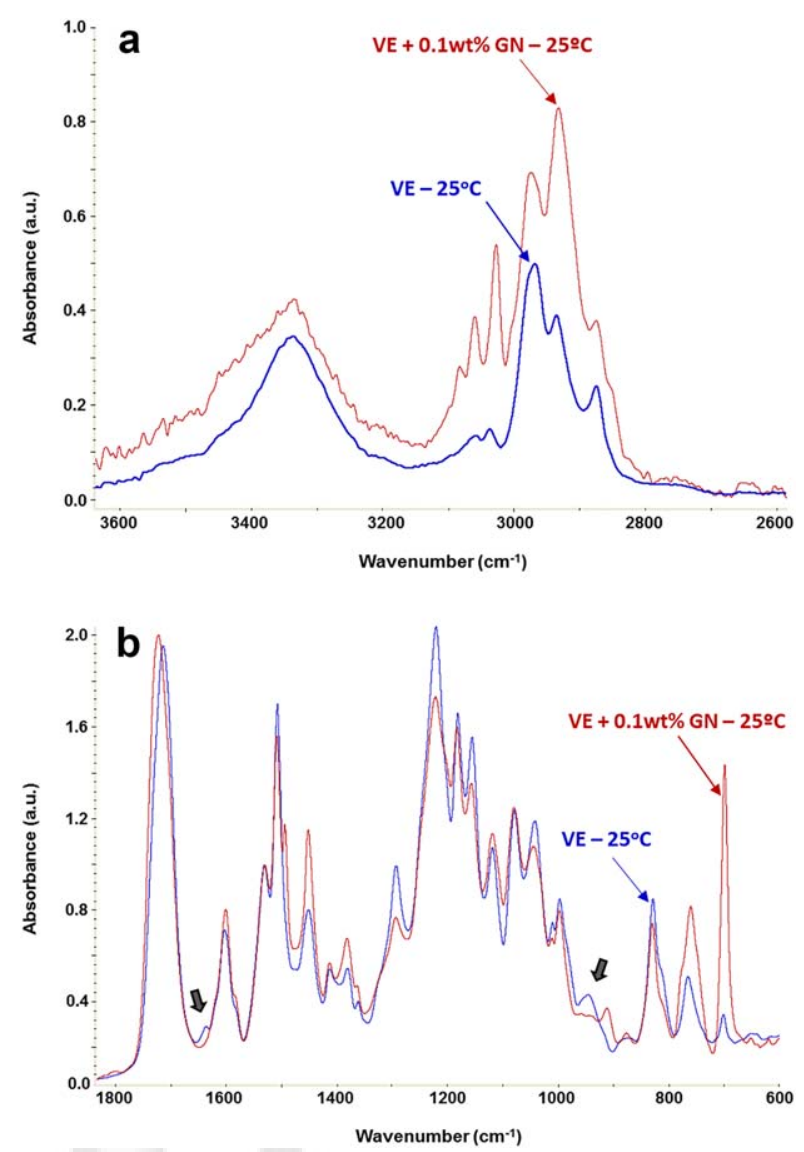

FIG. 5. (a) ATR-IR spectra of the VE and the VE $+0.1 \mathrm{wt} \%$ GN cured at $25^{\circ} \mathrm{C}$. $2,600-3,600 \mathrm{~cm}^{-1}$ region. (b) ATR-IR spectra of the VE and the $\mathrm{VE}+0.1 \mathrm{wt} \% \mathrm{GN}$ cured at $25^{\circ} \mathrm{C} .600-1,800 \mathrm{~cm}^{-1}$ region. [Color figure can be viewed at wileyonlinelibrary.com]

Figure 5a and $\mathrm{b}$ shows as typical example the ATR-IR spectra of the VE $+0.1 \mathrm{wt} \%$ GN composite cured at $25^{\circ} \mathrm{C}$ (all ATR-IR spectra of the VE-GN composites are similar irrespective of their GN content). The addition of GNs produces the disappearance of the bands at 946 and $1,637 \mathrm{~cm}^{-1}$ due to the double $\mathrm{C}=\mathrm{C}$ bonds in the $\mathrm{VE}$ monomer, indicating that the addition of GN (even $0.1 \mathrm{wt} \%$ only) may increase the extent of polymerization at $25^{\circ} \mathrm{C}$. Furthermore, new bands at $912(\mathrm{C}-\mathrm{H}$ groups $)$, 1,494 (aromatic ring) and $3,083(\mathrm{C}=\mathrm{C}$ in aromatic ring) $\mathrm{cm}^{-1}$ appear in the VE-GN composites cured at $25^{\circ} \mathrm{C}$. The expanded regions of the ATR-IR spectra of VE and $\mathrm{VE}+0.1 \mathrm{wt} \%$ GN (Fig. 5a and b) evidence a displacement of the bands of the aromatic ring at 3,037, 870 and $765 \mathrm{~cm}^{-1}$ to $3,027,877$ and $760 \mathrm{~cm}^{-1}$, respectively, a displacement of the band of methylene groups from 2,968 to $2,975 \mathrm{~cm}^{-1}$, and a displacement of the $\mathrm{C}=\mathrm{O}$ band from 1,715 to $1,724 \mathrm{~cm}^{-1}$. All these changes suggest that the addition of GN produces some changes in the chemical structure of the composite.

The chemical changes in the VE-GN composites with respect to the VE polymer can be ascribed to the existence of interactions via hydrogen or covalent bond between the $\mathrm{OH}$ and $\mathrm{C}=\mathrm{O}$ groups of the $\mathrm{VE}$ monomer, 


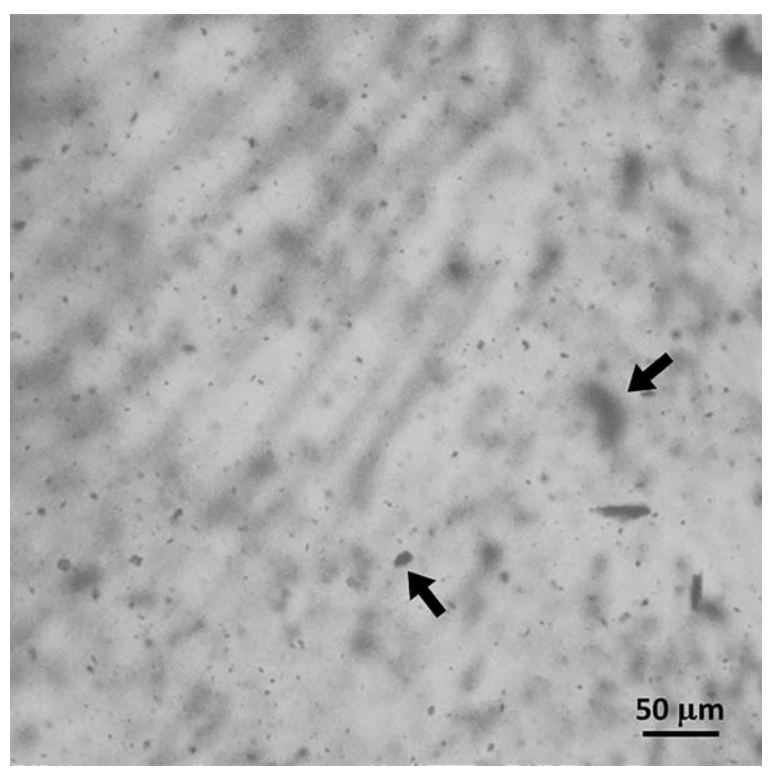

FIG. 6. Confocal micrograph of the VE $+0.1 \mathrm{wt} \% \mathrm{GN}$ composite cured at $25^{\circ} \mathrm{C}$.

and the carbon-oxygen and $\mathrm{OH}$ groups on the edges of the GNs. The bonds produced between the $\mathrm{OH}$ groups of the $\mathrm{VE}$ monomer and the $\mathrm{C}=\mathrm{O}$ groups on the edges of the GNs, and the ones between the $\mathrm{OH}$ groups on the edges of the GNs and the $\mathrm{C}=\mathrm{O}$ groups of the VE monomer may alter the kinetics and extent of polymerization of the monomer on the nanoplatelet edges, i.e. the GN edges may act as new centres for polymerization of the monomer. In fact, the existence of strong physical interactions, such as hydrogen and covalent bonding, between the oxygen-containing functionalities on the surface of carbon fibres and the ester and alcohol functionalities in the vinyl ester monomers has been demonstrated experimentally by Vautard et al. [31]. Similarly, the existence of interactions between oxidized and non-oxidized graphene and VE monomer has been evidenced by molecular dynamic studies [32, 33]. Furthermore, Dirand et al. [34] showed that the surface chemistry of a nanoparticle favoured the polymerization of the VE monomer in the vicinity of the nanoparticle surface, leading to very thick interphases.

The nanoparticles of $\mathrm{GN}$ are well dispersed into the $\mathrm{VE}+\mathrm{GN}$ composite matrix. In fact, Figure 6 shows, as typical example, the confocal micrograph of the $\mathrm{VE}+0.1 \mathrm{wt} \%$ GN composite, in which the nanoplatelets appear well-distributed into the polymer matrix without evidence of agglomeration, supporting the availability of the VE monomer to the edges of the nanoplatelets. Figure 7 shows, as typical example, the SEM micrograph of the $\mathrm{VE}+1 \mathrm{wt} \%$ GN composite in which the nanoplatelets appear homogeneously distributed in the matrix and they are not agglomerated, and a good interfacial interaction between the GNs and the VE matrix can be noticed.

Ziaee and Palmese [35] proposed the existence of phase separation in the VE polymer matrix due to the insolubility of the partially crosslinked and the fully crosslinked polymer fractions, i.e. two phases can be distinguished in the matrix, one phase rich in fully crosslinked polymer and the other rich in partially crosslinked polymer. The partially crosslinked polymer trapped in the fully polymer network cannot react under isothermal conditions because of vitrification, and the full polymerization of the VE polymer cannot be produced. Considering that the dispersion of the GN particles into the VE monomer is good, an alteration of the phase separation in the VE polymer can be anticipated in the VE + GN composites, i.e. the amount of partially crosslinked polymer trapped into the matrix would be different and the new morphologies will affect the polymerization.

The interactions between the VE polymer and the GNs in the composites were also studied by Raman spectroscopy. Figure $8 \mathrm{a}$ and $\mathrm{b}$ shows two regions of the Raman spectra of the VE polymer and the VE $+5 \mathrm{wt} \%$ GN composite. The Raman spectrum of the VE $+5 \mathrm{wt} \%$ GN composite shows new bands at 1,114, 1,236, 2,610 and 2,761 $\mathrm{cm}^{-1}$, and several bands due to methylene, aromatic ring and $\mathrm{C}-\mathrm{O}$ groups are displaced to different wavenumbers. Although the Raman spectrum of the GNs shows some bands in the vicinity of the wavenumbers of the new bands in the spectrum of the $\mathrm{VE}+5 \mathrm{wt} \%$ GN composite, their intensity should be very small because of its low amount. In agreement with the ATR-IR spectroscopy results, the presence of new bands evidences changes in the chemical environment of the aromatic ring, $\mathrm{C}-\mathrm{O}$ and methylene groups in the $\mathrm{VE}+\mathrm{GN}$ composites, thus confirming the existence of interactions between the VE and the graphite nanoplatelets.

The cure of the VE monomer is completed at temperatures above $100^{\circ} \mathrm{C}[26,35]$, and therefore, the addition of GN is not expected to produce noticeable structural changes in the $\mathrm{VE}+\mathrm{GN}$ composites cured at $100^{\circ} \mathrm{C}$. Figure 9 shows the ATR-IR spectra of the VE polymer and the $\mathrm{VE}+\mathrm{GN}$ composites cured at $100^{\circ} \mathrm{C}$. Upon adding GN, no new bands appear in the ATR-IR spectra, and similar spectra are obtained in the VE polymer and the composites, irrespective of their GN content.

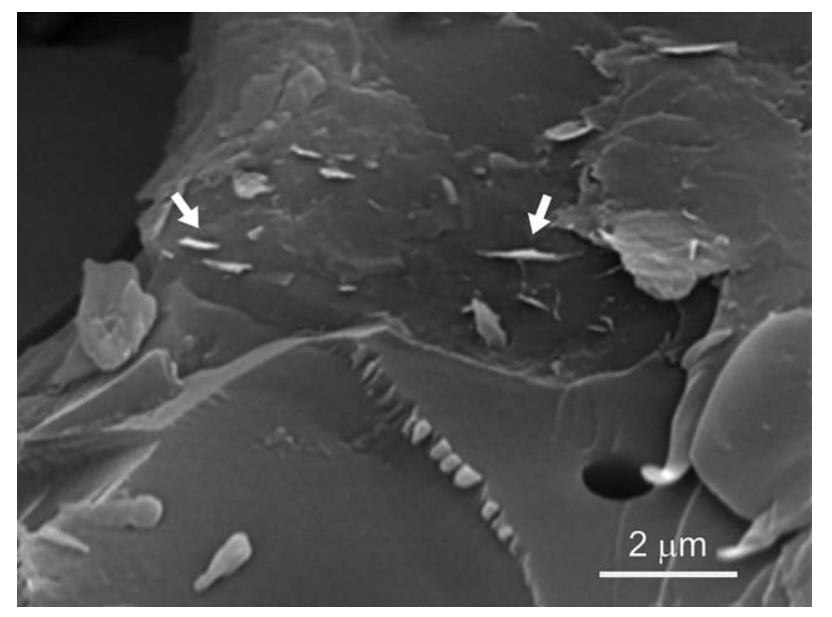

FIG. 7. SEM micrograph of the VE $+1 \mathrm{wt} \%$ GN composite cured at $25^{\circ} \mathrm{C} .10,000 \times$. 

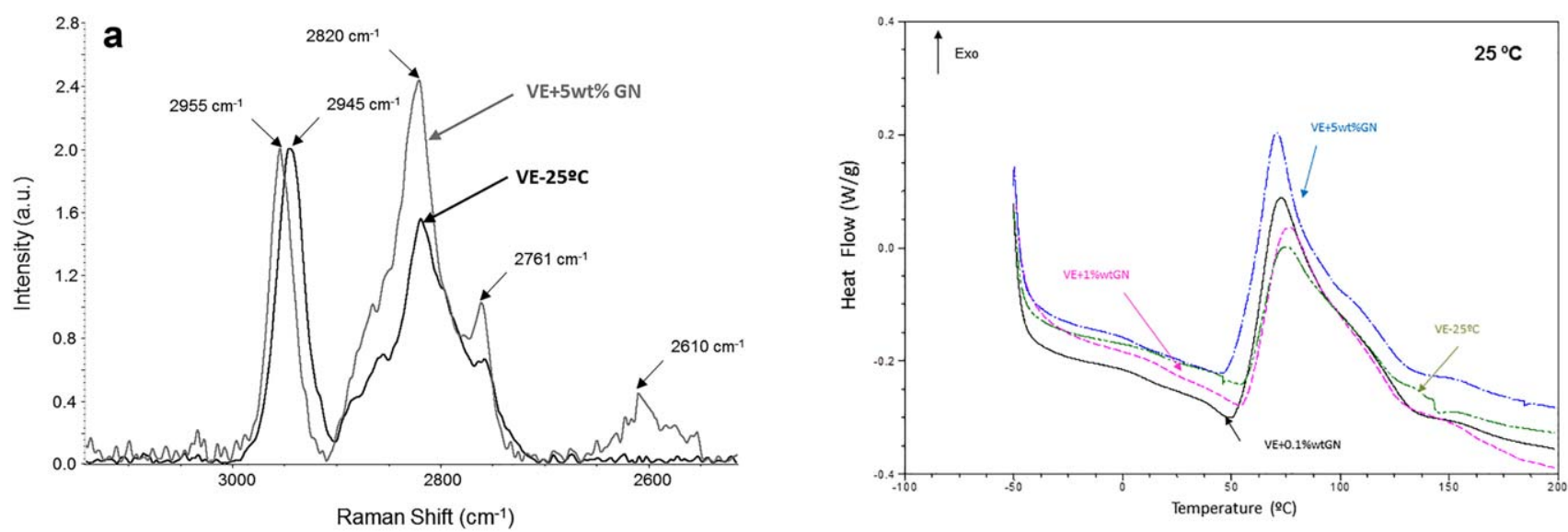

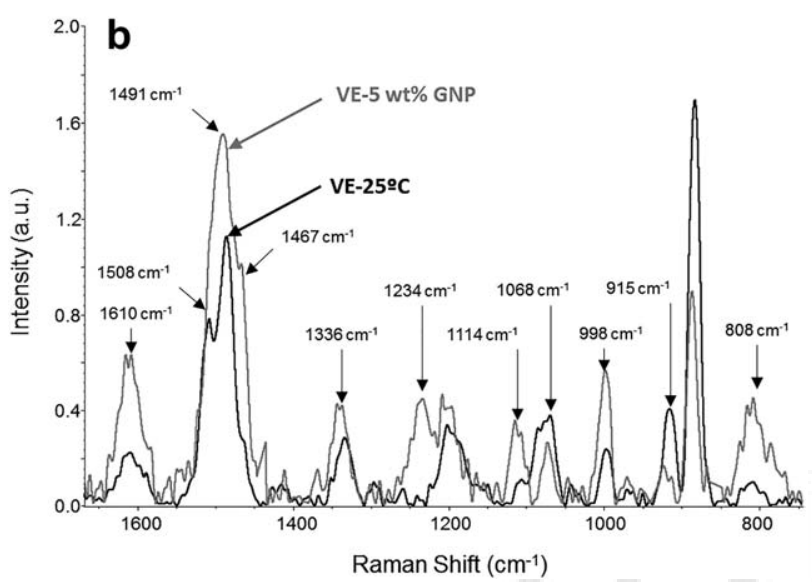

FIG. 8. (a) Raman spectra of the VE polymer and the VE $+5 \mathrm{wt} \%$ GN composite cured at $25^{\circ} \mathrm{C}$. Region of 2,550-3,300 $\mathrm{cm}^{-1}$. (b) Raman spectra of the VE polymer and the VE $+5 \mathrm{wt} \%$ GN composite cured at $25^{\circ} \mathrm{C}$. Region of $750-1,720 \mathrm{~cm}^{-1}$.

\section{Thermal Properties of the VE-GN Composites}

Figure 10 shows the DSC thermograms corresponding to the first heating run of the $\mathrm{VE}$ polymer and the $\mathrm{VE}+\mathrm{GN}$ composites cured at 25 and $100^{\circ} \mathrm{C}$. All DSC thermograms show an incomplete cure at $25^{\circ} \mathrm{C}$ which is

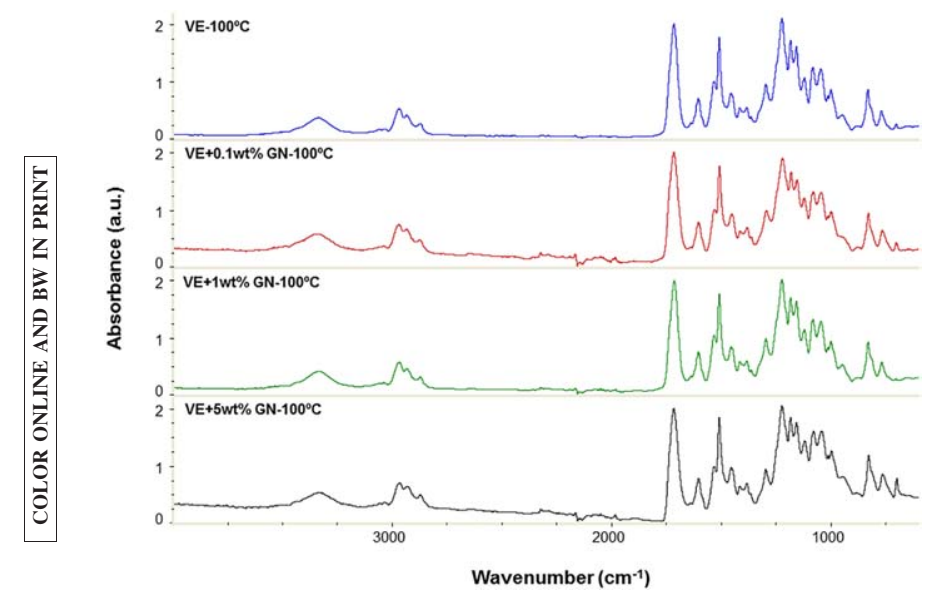

FIG. 9. ATR-IR spectra of the VE polymer and the VE + GN composites cured at $100^{\circ} \mathrm{C}$. [Color figure can be viewed at wileyonlinelibrary.com]

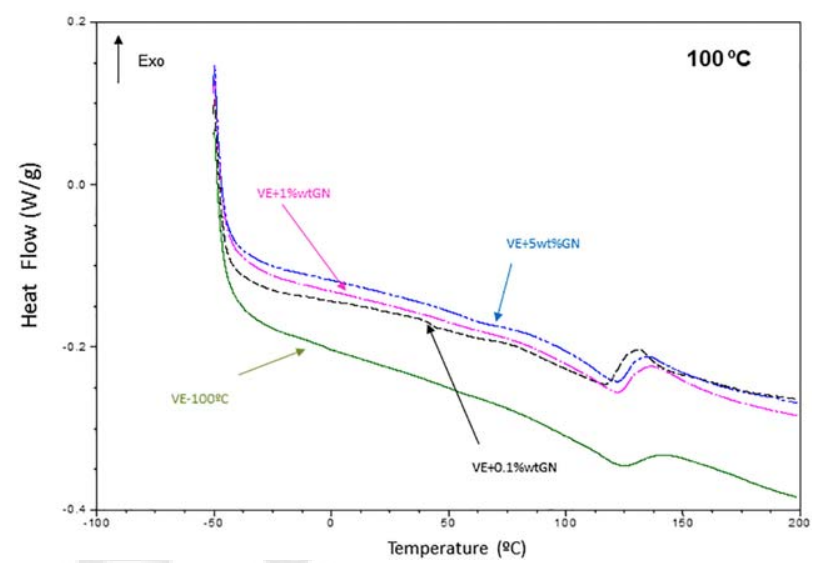

FIG. 10. DSC thermograms of the VE polymer and the VE $+\mathrm{GN}$ composites cured at 25 and $100^{\circ} \mathrm{C}$. First heating run. [Color figure can be viewed at wileyonlinelibrary.com]

evidenced by the exothermal post-cure peak that appears just after the end of the glass transition. The temperature $\left(T_{\mathrm{c}}\right)$ at which the post-cure of the $\mathrm{VE}+\mathrm{GN}$ composites cured at $25^{\circ} \mathrm{C}$ appears is slightly lower than in the VE polymer. When the composites are cured at $100^{\circ} \mathrm{C}$, a small post-cure appear at noticeably higher temperature than in the ones cured at $25^{\circ} \mathrm{C}$.

It was unexpected that the existence of interactions between the GNs and the VE monomer produces the post-cure of the partially crosslinked polymer during the DSC experiment at lower temperature than in the unfilled VE polymer. An increase in the viscosity was observed during the mixing of the VE monomer and the graphite nanoplatelets, and this can affect the kinetics of the free radical polymerization. On the other hand, because of the VE monomer on the GNs will polymerize on their surface, it is feasible that the formation of partially crosslinked polymer can be favoured with respect to the ones in the free VE monomer, and there is a higher chance of trapping some oligomers and partially crosslinked polymer in the confined area created by the polymer chains that grow in the vicinity of the nanoplatelets. As a consequence, the fraction of the partially polymerized polymer cured at $25^{\circ} \mathrm{C}$ will be lower than in the VE polymer without GNs, and therefore, the post-cure during the DSC 
TABLE 1. $T_{\mathrm{g}}$ values of the VE polymer and VE + GN composites cured at 25 and $100^{\circ} \mathrm{C}$. Second DSC heating run.

\begin{tabular}{lcccc}
\hline & \multicolumn{4}{c}{$T_{\mathrm{g}}\left({ }^{\circ} \mathrm{C}\right)$-2nd DSC heating run } \\
\cline { 2 - 5 } $\begin{array}{l}\text { Curing } \\
\text { temperature } \\
\left({ }^{\circ} \mathrm{C}\right)\end{array}$ & $\mathrm{VE}$ & $\mathrm{VE}+0.1 \mathrm{wt} \%$ & $\mathrm{VE}+1 \mathrm{wt} \%$ & $\mathrm{VE}+5 \mathrm{wt} \%$ \\
\hline 25 & 110 & 120 & $\mathrm{GN}$ & $\mathrm{GN}$ \\
100 & 118 & 117 & 116 & 119 \\
\hline
\end{tabular}

experiment will start at lower temperature and the enthalpy of post-polymerization will be higher than in the VE polymer without GNs.

The addition of GNs increases the glass transition temperature of the composites obtained from the second DSC heating run of the VE polymer (Table 1), more noticeably when the cure is carried out at $25^{\circ} \mathrm{C}$. Similar findings were obtained by Liao et al. [36] by adding carbon nanotubes to VE and it has been ascribed to the intercalation of the carbon filler between the polymer chains. In the VE-GN composites, the increase in the $T_{\mathrm{g}}$ value can also be ascribed to the interactions between the graphite nanoplatelets and the VE polymer.

The structural changes in the $\mathrm{VE}+\mathrm{GN}$ composites also affect to their thermal stability that was assessed by

F11 TGA (Fig. 11). The addition of GN increases the thermal stability of the composites cured at $25^{\circ} \mathrm{C}$ to a greater extent by increasing the GN content, and it is particularly evidenced in the thermal decompositions produced below $300^{\circ} \mathrm{C}$. The residual mass of the VE polymer at the end of the TGA experiment carried out under inert atmosphere is $4 \mathrm{wt} \%$, and the amount of carbonized residue in the $\mathrm{VE}+\mathrm{GN}$ composites is higher $(5-10 \mathrm{wt} \%)$ and increases by increasing the loading of GNs in the composite. The residual masses in the VE polymer and the $\mathrm{VE}+\mathrm{GN}$ composites are due to char formation during TGA experiment carried out under inert atmosphere and to residual GNs because of they are null when at $800^{\circ} \mathrm{C}$ the atmosphere in the TGA experiment is changed to air. On the other hand, the TGA thermograms of the $\mathrm{VE}+\mathrm{GN}$ composites cured at $100^{\circ} \mathrm{C}$ are similar irrespective of the GNs content but their thermal stability is higher than for the VE polymer.

\section{Viscoelastic Properties of the VE-GN Composites}

The addition of GNs changes the viscoelastic properties of the composites. The variation of the storage modulus and tan delta as a function of the temperature for the $\mathrm{VE}$ polymer and the $\mathrm{VE}+\mathrm{GN}$ composites is shown in F12 Fig. 12a and b, respectively.

The variation of the storage modulus as a function of the temperature in the VE-GN composites cured at $25^{\circ} \mathrm{C}$ (Fig. 12a) shows that in the glassy region the storage modulus decreases by increasing the amount of GNs in the composite and, once the glass transition is initiated, an increase in the storage modulus is produced. This increase in the storage modulus in the VE polymer during the glass transition in an indication of the existence of vitrification and by increasing the temperature during the DMTA experiment the storage modulus increases due to the post-cure of the partially crosslinked polymer fraction; once this fraction is completely crosslinked, the glass transition can be distinguished by a continuous decrease in the storage modulus at high temperature until the rubbery plateau is reached. However, when the VE + GN composites are cured at $100^{\circ} \mathrm{C}$, the storage modulus decreases continuously once the glass transition is produced, and the post-cure and the vitrification are not evidenced confirming the complete cross-linking of the composite. These results are in agreement with a previous study on the cure kinetics of VE resin [37].

The variation of the tan delta as a function of the temperature (Fig. 13b) in the VE polymer and the VE + GN composites cured at $25^{\circ} \mathrm{C}$ shows two alpha relaxations due to the partially crosslinked polymer and/or residual styrene, and to the cross-linked polymer network. When the composite is cured at $100^{\circ} \mathrm{C}$, a unique alpha relaxation of the fully cross-linked VE polymer can be distinguished at $132^{\circ} \mathrm{C}$ and its tan delta value is near 1 .
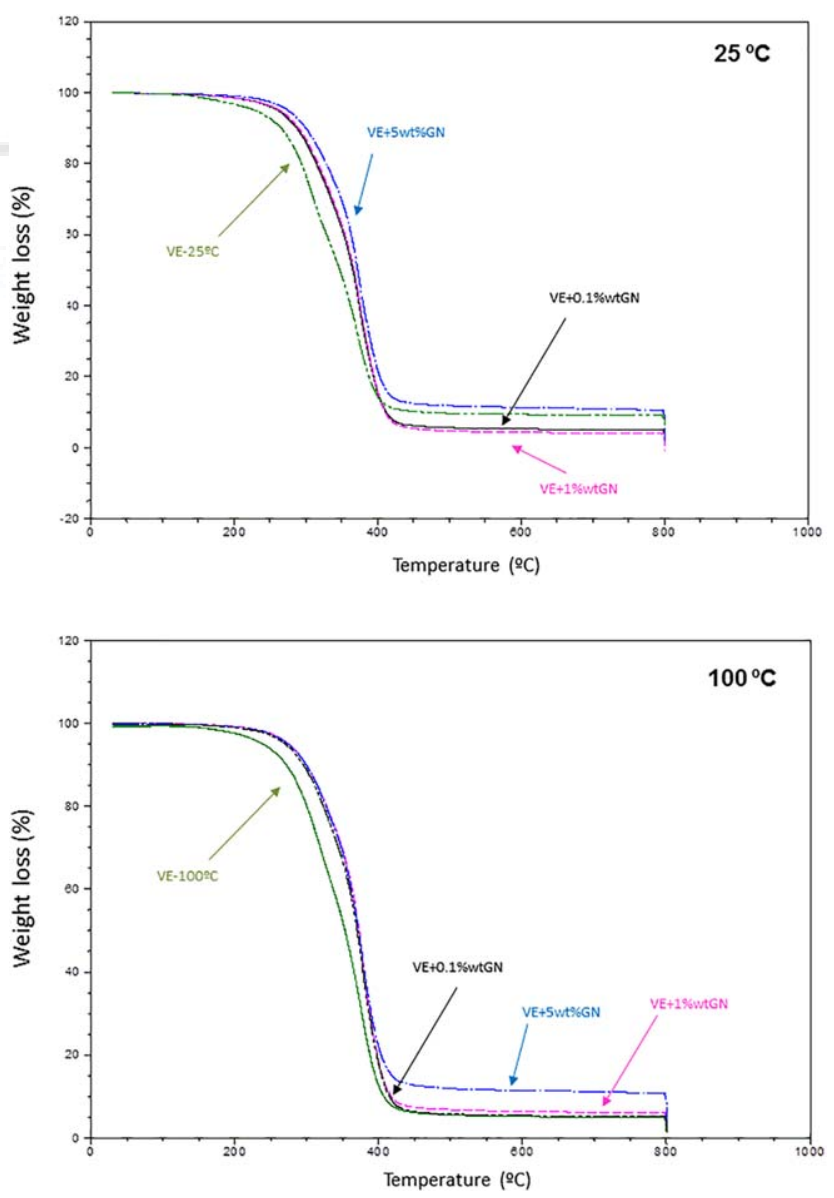

FIG. 11. Variation of the weight loss as a function of the temperature for the VE polymer and the VE + GN composites cured at 25 and $100^{\circ}$. [Color figure can be viewed at wileyonlinelibrary.com] 
a
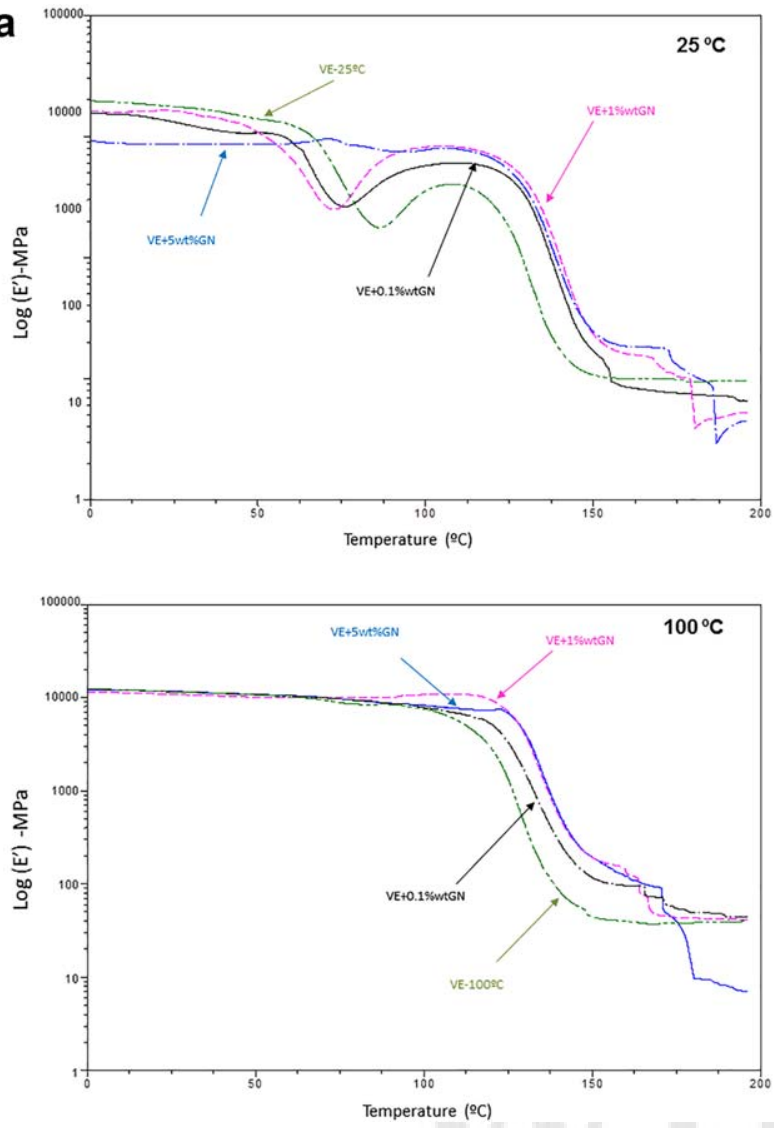

b
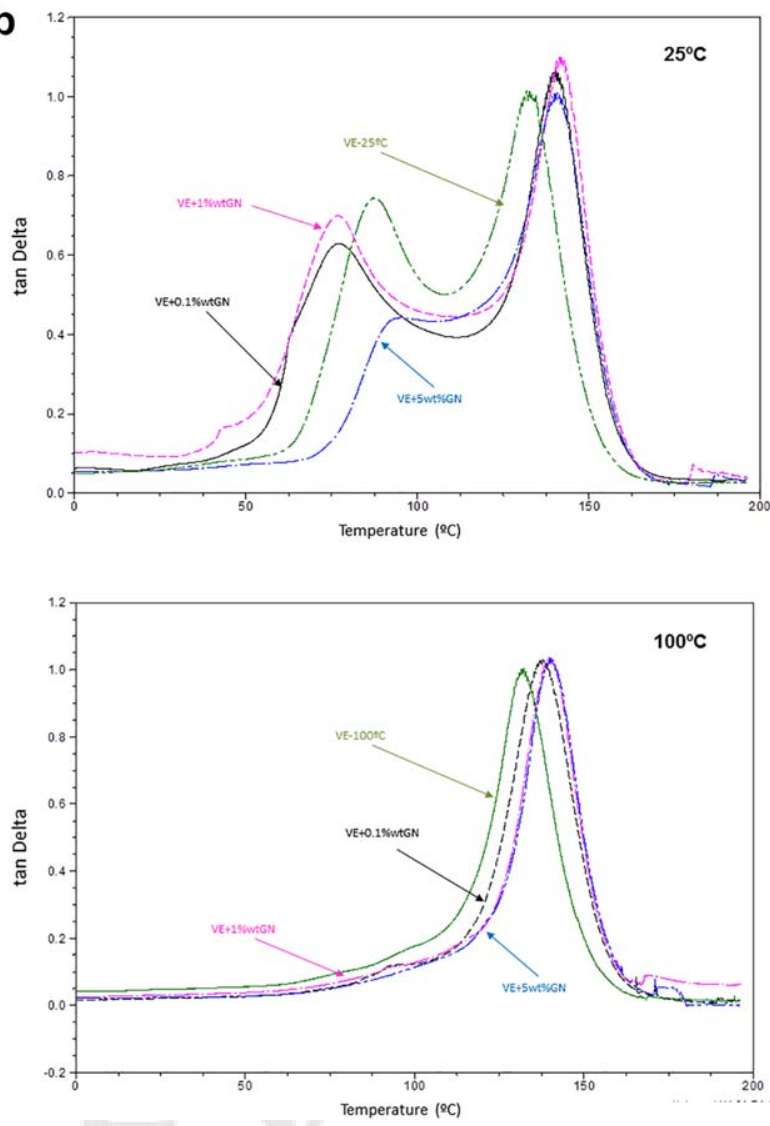

FIG. 12. (a) Variation of the storage modulus as a function of the temperature of the VE polymer and the $\mathrm{VE}+\mathrm{GN}$ composites cured at 25 and $100^{\circ} \mathrm{C}$. (b) Variation of the loss factor $(\tan \delta$ ) as a function of the temperature of the $\mathrm{VE}$ polymer and the $\mathrm{VE}+\mathrm{GN}$ composites cured at 25 and $100^{\circ} \mathrm{C}$. [Color figure can be viewed at wileyonlinelibrary.com]

Therefore, the cure at $100^{\circ} \mathrm{C}$ produced a complete crosslinked composite. It has been shown [38] that the DMA experiments of the VE polymer evidenced the existence of beta relaxation at $-60^{\circ} \mathrm{C}$ or lower temperature, and one or two alpha relaxations at higher temperature. The existence of two peaks in the tan delta vs temperature plots of the VE polymer has been ascribed to one alpha relaxation over $90^{\circ} \mathrm{C}$ due to the $T_{\mathrm{g}}$ of the non-completely crosslinked polymer, and another one at around $120^{\circ} \mathrm{C}$ that corresponds to the $T_{\mathrm{g}}$ of the fully crosslinked polymeric chains [39-41]. The temperature of the peak at higher temperature in the plots of tan delta vs temperature of the VE polymer cured at $25^{\circ} \mathrm{C}$ (Fig. 12b) is almost the same than for the one post-cured at $100^{\circ} \mathrm{C}$ and corresponds to the glass transition temperature of the fully crosslinked composites.

It has been shown that the temperature at which the alpha relaxation at lower temperature in the VE polymer appears depended on its cure extent [40]. According to Fig. $12 \mathrm{~b}$, the relaxation at $90^{\circ} \mathrm{C}$ of the VE polymer cured at $25^{\circ} \mathrm{C}$ due to the partially crosslinked polymer fraction in the matrix is displaced to lower temperature $\left(75^{\circ} \mathrm{C}\right)$ in the composites containing $0.1-1 \mathrm{wt} \% \mathrm{GN}$ and a slight decrease in tan delta value $(0.65-0.70)$ is also produced.
The value of tan delta is related to the ratio of the loss and the storage modulus of the polymers, and a decrease in tan delta indicates a decrease in the loss modulus and/ or an increase in the storage modulus. In the $\mathrm{VE}+\mathrm{GN}$ composites several factors can be involved in the decrease of the tan delta value, such as the higher extent of reaction due to the cure of the partially crosslinked polymer fraction in the matrix. The polymerization of the VE monomer on the GN surface will be likely uncompleted during cure at $25^{\circ} \mathrm{C}$, and furthermore some oligomers and partially crosslinked polymer can be trapped in the vicinity of the nanoparticles; consequently, the fraction of the partially crosslinked polymer will be higher in VE + GN composite than in the VE polymer. Consequently, the post-cure during the DMTA experiment will start at lower temperature and the value of tan delta will be lower than in the VE polymer without GN. On the other hand, the $\mathrm{VE}+5 \mathrm{wt} \%$ GN composite cured at $25^{\circ} \mathrm{C}$ shows a structural relaxation at $90^{\circ} \mathrm{C}$ (similarly to the VE polymer) with much smaller tan delta value $(0.45)$, because of the polymerization of the partially crosslinked polymer in the matrix. In fact, once the fraction of the partially crosslinked polymer of the composites is cured, an increase of the temperature of the relaxation at higher temperature of 

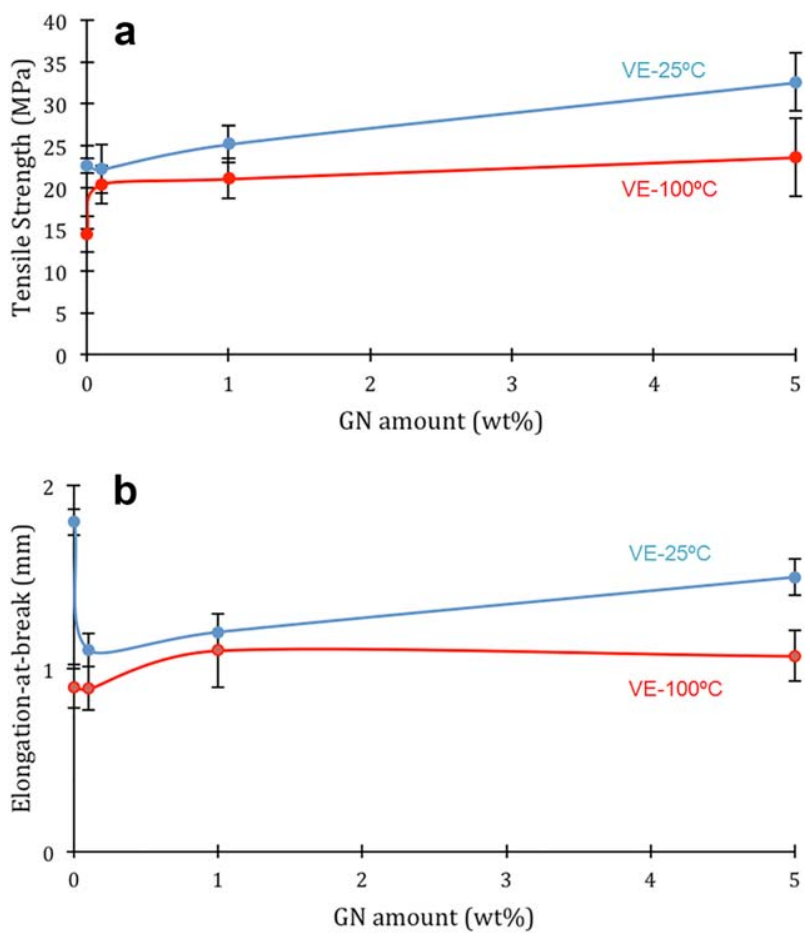

FIG. 13. (a) Variation of the tensile strength of the VE polymer and the $\mathrm{VE}+\mathrm{GN}$ composites cured at 25 and $100^{\circ} \mathrm{C}$ as a function of their GNs content. (b) Variation of the elongation-at-break of the VE polymer and the VE $+\mathrm{GN}$ composites cured at 25 and $100^{\circ} \mathrm{C}$ as a function of their GNs content. [Color figure can be viewed at wileyonlinelibrary. com]

the composites is produced with respect to that of the VE polymer (Fig. 12b), in agreement with the evidences shown by DSC, i.e. the relaxation temperature of the VEGN composites appears at $131-141^{\circ} \mathrm{C}$ (the glass transition temperature of the $\mathrm{VE}$ polymer is $120^{\circ} \mathrm{C}$ ), irrespective of the GN content in the composites. Therefore, the addition of the GNs produces an increase in the elastic modulus of the $\mathrm{VE}+\mathrm{GN}$ composites cured at $25^{\circ} \mathrm{C}$ at $75-90^{\circ} \mathrm{C}$ and a decrease in tan delta value, which can be associated to the cure of the partially crosslinked polymer fraction in the matrix.

The variation of the tan delta as a function of the temperature in the $\mathrm{VE}+\mathrm{GN}$ composites cured at $100^{\circ} \mathrm{C}$ (Fig. 12b) shows only one relaxation due to the fully crosslinked polymer network. The relaxation due to the partially crosslinked polymer fraction and/or residual styrene at $93^{\circ} \mathrm{C}$ is quite small in $\mathrm{VE}+01 \mathrm{wt} \% \mathrm{GN}$ and $\mathrm{VE}+1 \mathrm{wt} \%$ GN composites, and it is not present in $\mathrm{VE}+5 \mathrm{wt} \% \mathrm{GN}$. The addition of the GNs increases the $T_{\mathrm{g}}$ value of the $\mathrm{VE}$ polymer, in greater extent by increasing the amount of GN up to $1 w t \%$, because of the interactions between the GNs and the polymer in the composites.

\section{Mechanical Properties of the VE-GN Composites}

Because of the enhanced properties of the $\mathrm{VE}+\mathrm{GN}$ composites cured at $25^{\circ} \mathrm{C}$ due to the combination of the filler effect and the interactions between the graphite nanoplatelets and the matrix, improved mechanical properties can be expected. Figure 13a shows the variation of the tensile strength of the VE polymer and the VE + GN composites cured at 25 and $100^{\circ} \mathrm{C}$ as a function of their GN content. The addition of the GNs increases the tensile strength, irrespective of the cure temperature. When the $\mathrm{VE}+\mathrm{GN}$ composite is cured at $25^{\circ} \mathrm{C}$, the tensile strength increases more noticeably by increasing the amount of GNs, whereas the tensile strength of the $\mathrm{VE}+\mathrm{GN}$ composites cured at $100^{\circ} \mathrm{C}$ is similar irrespective of their GNs amount. Furthermore, the tensile strength of the VE polymer cured at $25^{\circ} \mathrm{C}$ is higher than in the composites, and the differences in the tensile strength in the composites cured at 25 and $100^{\circ} \mathrm{C}$ are dramatically reduced when $0.1 w t \%$ GNs are added. These trends agree well with the variation in the storage modulus in the glassy region measured by DMTA. When the VE + GN composite is cured at $25^{\circ} \mathrm{C}$, a certain plastic deformation under load due to the partially crosslinked polymer in the matrix is produced, and the addition of the GNs restrains the deformation of the polymeric matrix causing the mechanical reinforcement of the composite, i.e. an increase in the tensile strength is produced, the reinforcement is more noticeable by increasing the amount of GNs in the composite. However, when the $\mathrm{VE}+\mathrm{GN}$ composites are cured at $100^{\circ} \mathrm{C}$, they are almost fully cross-linked, and they will have a lower capacity of deformation under load. Under these circumstances, the increase in the GNs content has a negligible effect in the mechanical properties of the composites cured at $100^{\circ} \mathrm{C}$ that will be mainly controlled by the properties of the matrix.

Figure $13 \mathrm{~b}$ shows the variation of the elongation-atbreak of the $\mathrm{VE}+\mathrm{GN}$ composites cured at 25 and $100^{\circ} \mathrm{C}$ as a function of the amount of GNs. Similar to the trend found in the tensile strength, the elongation-at-break is higher in the $\mathrm{VE}+\mathrm{GN}$ composites cured at $25^{\circ} \mathrm{C}$ than at $100^{\circ} \mathrm{C}$, irrespective of the amount of GNs. The elongation-at-break of the $\mathrm{VE}$ polymer cured at $25^{\circ} \mathrm{C}$ is higher because of the partially crosslinked polymer in the matrix and/or residual styrene in the polymer imparts some toughness; consequently, when the VE polymer is cured at $100^{\circ} \mathrm{C}$, lower amount of partially crosslinked polymer in the matrix and/or residual styrene exists, and lower elongation-at-break is obtained.

\section{CONCLUSIONS}

Addition of graphite nanoplatelets affected the extent of cross-linking of the vinylester cured at $25^{\circ} \mathrm{C}$, primarily because of two effects: (i) Hydrogen bond or covalent bond formation between the carbon-oxygen and $\mathrm{OH}$ species on the $\mathrm{GN}$ edges and the $\mathrm{OH}$ and $\mathrm{C}=\mathrm{O}$ groups of the VE monomer; and (ii) the change in the extent of phase separation between the domains of the partially and the fully crosslinked polymer fractions in the matrix. The GN particles were well dispersed into the VE matrix, and good interfacial interaction was observed. The higher 
crosslink of the composites cured at $25^{\circ} \mathrm{C}$ was evidenced by an increase in their glass transition temperature, an increase in their thermal stability and an increase in their storage modulus. The structural relaxation of the partially crosslinked VE polymer at $90^{\circ} \mathrm{C}$ in the composites cured at $25^{\circ} \mathrm{C}$ was displaced to lower temperature $\left(75^{\circ} \mathrm{C}\right)$ and lower tan delta value when $0.1-1 \mathrm{wt} \% \mathrm{GN}$ was added. Finally, the tensile strength and elongation-at-break increased in the composites cured at $25^{\circ} \mathrm{C}$ because of the GNs restrained the deformation of the polymeric matrix, but the increase in the GNs content had a negligible effect on the mechanical properties of the composites cured at $100^{\circ} \mathrm{C}$.

\section{REFERENCES}

1. M.B. Launikitis, "Vinyl Ester Resin," in Handbook of Composites, G. Lubin, Ed., Van Nostrand Reinhold, New York, 38-49 (1982).

2. B. Gaur and J.S.P. Rai, Eur. Polym. J., 29, 1149 (1993).

3. P. Siva, I.K. Varma, D.M. Patel, and T.J.M. Sinha, Bull. Mater. Sci., 17, 1095 (1994).

4. C. Alia, M.V. Biezma, P. Pinilla, J.M. Arenas, and J.C. Suárez, Adv. Mater. Sci. and Eng. (2013). Article ID 869075.

5. M. Sultania, S.B. Yadaw, J.S.P. Rai, and D. Srivastava, Mater. Sci. Eng. A, 527, 4560 (2010).

6. S. Agarwal, A. Mishra, and J.S.P. Rai, J. Appl. Polym. Sci., 87, 1948 (2003).

7. K. Li, K. Wang, M. Zhan, and W. Xu, Polym. Degrad. Stab., 98, 2340 (2013).

8. M. Sultania, J.S.P. Rai, and D. Srivastava, Eur. Polym. J., 46, 2019 (2010).

9. C.M. Laot, E. Marand, and H.T. Oyama, Polymer, 40, 1095 (1999).

10. S. Stankovich, D.A. Dikin, G.H.B. Dommett, K.M. Kohlhaas, E.J. Zimney, E.A. Stach, R.D. Piner, S.B.T. Nguyen, and R.S. Ruoff, Nature, 442, 282 (2006).

11. S. Ansari and E.P. Giannelis, J. Polym. Sci. B: Polym. Phys., 47, 888 (2009).

12. T. Ramanathan, A.A. Abdala, S. Stankovich, D.A. Dikin, M.H. Alonso, R.D. Piner, D.H. Adamson, H.C. Schniepp, X. Chen, R.S. Ruoff, S.T. Nguyen, I.A. Aksay, R.K. Prud'Homme, and L.C. Brinson, Nat. Nanotechnol., 3, 327 (2008).

13. Y.R. Lee, A.V. Raghu, H.M. Jeong, and B.K. Kim, Macromol. Chem. Phys., 210, 1247 (2009).

14. J.K. Park, I.H. Dob, P. Askeland, and L.T. Drzal, Compos. Sci. Technol., 68, 1734 (2008).

15. W.-F. Ji, K.-C. Chang, M.-C. Lai, C.-W. Li, S.-C. Hsu, T.L. Chuang, J.-M. Yeh, and W.-R. Liu, Composites A, 65, 108 (2014).
16. K. Kalaitzidou, H. Fukushima, and L.T. Drzal, Composites A, 38, 1675 (2007).

17. S. Kim and L.T. Drzal, Composites A, 41, 581 (2010).

18. W.P. Wanga and C.Y. Pana, Polymer, 45, 3987 (2004).

19. Y.F. Zhao, M. Xiao, S.J. Wang, X.C. Ge, and Y.Z. Meng, Compos. Sci. Technol., 67, 2528 (2007).

20. W. Weng, G. Chen, D. Wu, X. Chen, J. Lu, and P. Wang, J. Polym. Sci. B: Polym. Phys., 42, 2842 (2004).

21. D. Cho, S. Lee, G. Yang, H. Fukushima, and L.T. Drzal, Macromol. Mater. Eng., 290, 179 (2005).

22. A. Chaturvedi, A. Tiwari, and A. Tiwari, Adv. Mater. Lett., 4, 656 (2013).

23. S. Swain, Trans. Electr. Electron. Mater., 14, 53 (2013).

24. $\cdots$

25. A. Almajid, L. Sorochynska, K. Friedrich, and B. Wetzel, Plast. Rubber Compos., 44, 50 (2015).

26. C. Alia, J.A. Jofre-Reche, J.C. Suárez, J.M. Arenas, and J.M. Martín-Martínez, J. Adhes. Sci. Technol., 29, 518 (2015).

27. O. Menesa, M. Cano, A. Benedito, E. Giménez, P. Castell, W.K. Maser, and A.M. Benito, Compos. Sci. Technol., 72, 1595 (2012).

28. E. Fuente, J.A. Menéndez, M.A. Díez, D. Suárez, and M.A. Montes-Morán, J. Phys. Chem. B, 107, 6350 (2003).

29. T. Kuila, S. Bose, A.K. Mishra, P. Khanra, N.H. Kim, and J.H. Lee, Prog. Mater. Sci., 57, 1061 (2012).

30. D. Yang, A. Velamakanni, G. Bozoklu, S. Park, M. Stoller, R.D. Piner, S. Stankovich, I. Jung, D.A. Field, C.A. Ventrice, Jr., and R.S. Ruoff, Carbon, 47, 145 (2009).

31. F. Vautard, S. Ozcan, and H. Meyer, Composites A, 43, 1120 (2012).

32. S. Nouranian, C. Jang, T.E. Lacy, S.R. Gwaltney, H. Toghiani, and C.U. Pittman, Jr., Carbon, 49, 3219 (2011).

33. C. Jang, S. Nouranian, T.E. Lacy, S.R. Gwaltney, H. Toghiani, and C.U. Pittman, Jr., Carbon, 50, 748 (2012).

34. X. Dirand, B. Hilaire, E. Lafontaine, B. Mortaigne, and M. Nardin, Composites, 25, 645 (1994).

35. S. Ziaee and G.R. Palmese, J. Polym. Sci. B: Polym. Phys., 37, 725 (1999).

36. S.H. Liao, M.C. Hsiao, C.Y. Yen, C.C.M. Ma, S.J. Lee, A. Su, M.C. Tsai, M.Y. Yen, and P.L. Liu, J. Power Sources, 195, 7808 (2010).

37. R.P. Brill and G.R. Palmese, J. Appl. Polym. Sci., 76, 1572 (2000).

38. J. Karger-Kocsis and O. Gryshchuk, J. Appl. Polym. Sci., 100, 4012 (2006).

39. X. Zhang, V. Bitaraf, S. Wei, and Z. Guo, AIChE J., 60, 266 (2014).

40. T.F. Scott, W.D. Cook, and J.S. Forsythe, Eur. Polym. J., 44, 3200 (2008).

41. W.D. Cook, G.P. Simon, P.J. Burchill, M. Lau, and T.J. Fitch, J. Appl. Polym. Sci., 64, 769 (1997). 
AQ1: Please check all the heading levels.

AQ2: Please provide complete details for Reference [24] in the reference list or delete the citation from the text, maintaining the numerical order of the references.

AQ3: Please check and provide the volume and page number for ref. 4.

AQ4: Please confirm that given names (red) and surnames/family names (green) have been identified correctly. 